\title{
A política de saúde no Brasil nos anos 90
}

\author{
Health Policy in Brazil in the 1990s
}

José Carvalho de Noronha 1

Laura Tavares Soares 1

\footnotetext{
1 Instituto de Medicina Social, Universidade do Estado do Rio de Janeiro. Rua São Francisco Xavier 524, 7ㅇ andar, Maracanã, 20550-013, Rio de Janeiro RJ. noronha@uerj.com.br
}

\begin{abstract}
The authors discuss trends in Brazilian health sector reform in the 1990s. They emphasize the dynamics of situational and structural changes which stigmatize the meaning of the Welfare State and thus end up undermining the basic solidarity characterizing the Social Security project (which included health). They also criticize the neoliberal model, which includes a privatist and narrow approach to the health sector, as compared to the model and principles of the Brazilian Unified Health System (SUS). Nevertheless, they identify various elements that can be used to reinvigorate the Health Reform process written into the 1988 Constitution.
\end{abstract}

Key words Health reform, Health policies, Neoliberal reforms
Resumo Os autores realizam uma reflexão sobre os rumos da reforma do setor saúde na década de 1990. Enfatizam a dinâmica de mudanças conjunturais e estruturais que, ao estigmatizar o sentido do Estado de Bem-Estar Social, acaba por minar as bases solidárias do projeto de seguridade social (no qual estava incluída a saúde). Fazem também a crítica ao modelo neoliberal que inclui, no seu interior, um pensamento privatista e focalizador sobre o setor saúde, quando comparado ao modelo e aos princípios do SUS. Mas ainda encontram vários elementos passíveis de serem articulados para revigorar o processo de construção da Reforma Sanitária que foi instituída na Constituição de 1988.

Palavras-chave Reforma sanitária, Políticas de saúde, Reformas neoliberais 


\section{O contexto dos anos 90}

Embora seja possível traçar uma análise da evolução do Setor Saúde de forma linear e isolada do contexto e identificar traços evolutivos significativos, defendemos a idéia de que na década de 1990 houve não apenas uma interrupção, mas um retrocesso no processo de construção de um projeto de Proteção Social para o Brasil que foi inscrito na Constituição de 1988. Esse projeto inscreveu a Saúde no marco de uma seguridade social pública, universal, garantidora de direitos de cidadania e que não tergiversava acerca da responsabilidade do Estado na sua implementação (art. 194). Além disso, seu artigo 196, ainda em pleno vigor, afirma que "A saúde é direito de todos e dever do Estado, garantido por políticas sociais e econômicas que visem à redução do risco de doença e outros agravos e ao acesso universal e igualitário às ações e serviços para sua promoção, proteção e recuperação".

A inflexão desse projeto de proteção social se dá num contexto de profundas mudanças econômicas, sociais e institucionais, determinadas pelas chamadas "reformas estruturais" conduzidas por políticas de ajuste, que insistimos em chamar de neoliberais - dada a sua matriz ideológico-política e o seu "receituário padrão" elaborado pelos organismos multilaterais de financiamento. Essas reformas foram implementadas em todos os países da América Latina, com graves conseqüências sociais e econômicas - cada dia mais visíveis -, implicando retrocessos históricos nos processos constitutivos de uma cidadania ainda incompleta, cujo exemplo mais radical foi o chileno, no início dos anos 80, e hoje é o argentino.

O Brasil, apesar da sua entrada "tardia" nesse processo, não fugiu à regra. As chamadas "reformas" vêm sendo perpetradas no Brasil desde o início da década de 1990, sob o argumento de que a Constituição Cidadã de 1988 seria o principal empecilho ao processo de "modernização" e "abertura" do país. No entanto, é na segunda metade dos anos 90 que praticamente se completa o projeto mais acabado (e neoliberal) de "Reforma do Estado".

A chamada área social no Brasil - com destaque para a área da saúde - constitui-se hoje o terreno mais conflitivo e exposto da nossa sociedade, na medida que é particularmente sensível às condições econômicas de restrição financeira impostas pelas políticas de ajuste econômico também implantadas em nosso país.
Estamos diante de uma situação social e de saúde onde se agravaram os "velhos" problemas - com o aumento absoluto da parcela da população que se encontra em situação de pobreza bem como se geraram "novos" problemas - sobretudo pelo desemprego e pela precariedade do trabalho, o que configura um quadro de uma enorme perversidade e complexidade, acompanhado de um terrível incremento das desigualdades sociais e econômicas. A este quadro se agrega, ainda, uma situação de desmonte do Estado brasileiro, o que tem levado a uma crescente desresponsabilização do governo federal das suas atribuições no terreno social.

As políticas de ajuste, determinadas em âmbito federal, têm trazido enormes limitações, com imposição de encargos adicionais, para as unidades da federação - em particular os municípios - no que diz respeito às respectivas capacidades de intervenção e de resposta frente às crescentes demandas sociais e de saúde. Isso tem gerado grandes iniqüidades, aprofundando ainda mais as desigualdades sociais e regionais.

As políticas sociais e de saúde perderam sua dimensão integradora, tanto no âmbito nacional como no âmbito regional e estadual, caindo numa visão focalista onde o "local" é privilegiado como o único espaço capaz de dar respostas supostamente mais "eficientes” e acordes às necessidades da população. Retrocedemos a uma visão "comunitária" onde as pessoas e as famílias passam a ser as responsáveis últimas por sua saúde e bem-estar. Por trás de um falso e importado conceito de empowerment está o abandono por parte do Estado de seu papel ativo e determinante nas condições de vida da população, particularmente quando parcelas majoritárias e crescentes da mesma estão na mais absoluta pobreza.

Este é o contexto onde se desenrola a política de Saúde nos anos 90, o qual não pode ser ignorado sob pena de cairmos no reducionismo e no "possibilismo" de soluções tecnocráticas para o setor saúde, com a aceitação acrítica de programas federais verticais e autoritários travestidos de "inovadores" e "modernos".

\section{A “reforma" do Estado ou a "contra-reforma"}

Em primeiro lugar gostaríamos de chamar a atenção para alguns aspectos preliminares ao debate em torno da reforma do Estado no Brasil, tais como: 
- os usos que têm sido feitos do termo "reforma”, esvaziando-o de qualquer conteúdo semântico específico e emprestando-lhe um caráter "mágico e infalível" na solução de todos os problemas nacionais;

- a necessidade de definir melhor, com mais clareza, qual é o Estado objeto da reforma e que aspectos precisam ser reformados; não sendo possível, dessa forma, impor uma receita padrão de reforma, assumindo, portanto, que existem diferentes possibilidades e propostas de reforma (em contraposição à “via única”); - qual é o diagnóstico no qual se baseia a reforma e quais as suas propostas de resolução dos problemas. As falsas premissas desse diagnóstico têm levado a falsas soluções. Um dos muitos exemplos é a "culpabilização" dos funcionários públicos por uma série de problemas no aparelho de Estado, o que tem focalizado as propostas da reforma no âmbito "administrativo" sobre o funcionalismo público federal;

- a não-existência de uma reforma "neutra" que seja "adequada e boa” para todo o país, identificando quais os interesses que estão em jogo. Este é sem dúvida um aspecto central na discussão: qual é o projeto político que está por trás da Reforma do Estado, e amparado por quem.

O movimento básico para corrigir as supostas "distorções" ou os "desvios" do Estado é a transferência para o setor privado daquelas atividades que podem ser "controladas pelo mercado". Isto é feito através da "privatização" de todas as estatais (sem qualquer tipo de distinção entre elas nem uma caracterização das mesmas como papel estratégico do Estado no desenvolvimento nacional) e da "descentralização" da execução de serviços (sociais) de educação, saúde, cultura e pesquisa científica a um setor "público não-estatal". Este setor emerge sem que se defina claramente como ele é constituído e quais são as regras para o seu funcionamento e, principalmente, para o seu financiamento e prestação de contas à sociedade.

Essas estratégias de Reforma do Estado estão inseridas em um movimento mais geral em direção a um suposto "setor público nãoestatal” (também chamado de Terceiro Setor) que se responsabilizaria pela execução dos serviços que não envolvessem o exercício do "poder de Estado", mas que deveriam ser subsidiados pelo Estado, como é o caso dos serviços de educação, saúde, cultura e pesquisa científica. Esse processo, chamado de "publicização", na realidade, não é uma "criação" do extinto
Ministério da Administração e Reforma do Estado. Ele se inclui em todas as propostas de reforma decorrentes da implementação dos chamados “ajustes estruturais". No entanto, mesmo naqueles países onde já existia uma certa tradição na participação de entidades não-estatais na prestação de serviços sociais, esse modelo vem sendo criticado na medida que não está dando conta de compensar a forte retração dos respectivos Estados tanto no financiamento como na gestão dos serviços públicos. $\mathrm{O}$ maior exemplo disso é o caso dos Estados Unidos, onde amplos setores da população encontram-se marginalizados do acesso a serviços sociais básicos, sejam eles estatais ou não.

A principal conseqüência desse tipo de processo tem sido a privatização dos serviços públicos na área social. A privatização da saúde no Brasil tem várias faces: algumas mais explícitas e outras ocultas ou travestidas de "modernização gerencial” no marco da já mencionada Reforma do Estado.

Por outro lado, os seguros privados encontram-se em crescente expansão. Trata-se de um setor duplamente beneficiado. De um lado, pela política de subfinanciamento das prestações do Sistema Único de Saúde, que "expulsa" clientela potencial para esses seguros: ou seja, com a sua política, o governo federal assegura um patamar de demanda para esses seguros. De outro, ele é privilegiado por um financiamento direto e indireto através de subsídios e isenções fiscais, o que tem representado um enorme desvio de recursos públicos para esse setor, abertamente, lucrativo, em detrimento do SUS.

Cabe apenas lembrar que esse privilegiamento tem limitações sérias, de natureza estrutural e financeira, já demonstradas em países onde se privatizou o setor saúde. Nos países latino-americanos, e o nosso não foge à regra, as possibilidades de expansão da demanda dos seguros privados é limitada à própria renda, particularmente da classe média, a qual, inclusive, vem empobrecendo a olhos vistos. Os dados do suplemento de saúde que acompanhou a Pesquisa Nacional de Amostragem Domiciliar do Instituto Brasileiro de Geografia e Estatística (IBGE), apurados em 1998, revelaram que apenas pouco menos de $25 \%$ estão cobertos por alguma forma de plano ou seguro de saúde. Isso significa que os restantes $75 \%$ (os mais empobrecidos) continuam dependendo do sistema público, cada dia mais desmontado e desfinanciado. 
Acrescente-se que o poder regulatório por parte do poder público sobre os seguros privados ainda tem se mostrado extremamente limitado: é do conhecimento de todos as numerosas restrições feitas por esse setor a determinadas clientelas e patologias que não dão lucro, sem falar na baixa qualidade da assistência prestada pelos serviços médicos contratados pelas companhias seguradoras, os quais são pessimamente remunerados em função dos lucros auferidos por essas empresas. Apesar do avanço regulatório ocorrido no Brasil com a aprovação de lei específica em 1998, o ano de 2001 tem assistido o crescimento de propostas visando à segmentação de coberturas assistenciais, buscando abrir perigosas brechas no incipiente marco legal de proteção dos direitos da parcela da população coberta por planos e seguros de saúde.

Outra face tão perversa quanto, mas talvez mais "camuflada", tem sido a privatização "por dentro" do setor público. Não bastasse a terceirização completa de serviços consolidada na contratação de agentes privados para prestação de serviços ambulatoriais, hospitalares e auxiliares de diagnóstico e terapia, concebida nos tempos do velho IAPI e consolidada no INAMPS, chegou-se à introdução da lógica mercantil no interior dos serviços públicos. Esta privilegia a uma não demonstrada "microeconomia” da relação custo/benefício em detrimento da qualidade. Sob o argumento da "modernização gerencial”, eliminou-se a figura do servidor público através da "flexibilização" e da "desregulamentação" das relações de trabalho, gerando um total descompromisso do serviço com a população atendida. As formas assumidas por essa "modernidade gerencial" são variadas, sendo as mais conhecidas as chamadas "cooperativas", camuflagem de precariedade dos contratos de trabalho e de evasão fiscal para o não recolhimento de contribuições sociais.

Essa é uma estratégia já explicitada na mal chamada Reforma do Estado, que transforma órgãos públicos estatais em agências privadas denominadas de Organizações Sociais, eufemismo que representa o descompromisso do Estado com a saúde da população, entregando-a nas mãos de agentes privados alavancados por recursos públicos. Em nome da "liberdade de escolha", essas agências podem, se quiserem, cobrar do usuário que estará pagando duplamente: através dos impostos e do pagamento direto pelos serviços. Ademais, essas agências apresentam a tendência estrutural de se despegarem dos órgãos de governos (ministérios) a que estão vinculadas, autonomizando-se da política setorial à qual deveriam estar subordinadas e dificultando mudanças de rumo nas suas políticas que deveriam se impor no caso da alternância democrática dos governos.

Aqui cabe chamar a atenção para o fato de que, lamentavelmente, a estratégia da cobrança direta dos usuários pelos serviços recebidos - preconizada em muitos documentos do Banco Mundial - já está sendo amplamente utilizada na maioria dos países latino-americanos. Isso significa que ainda temos muito que defender em nosso país: o SUS ainda é o único sistema público universal da América Latina, e, apesar das suas restrições e problemas, continua sendo a única alternativa que resta à parcela majoritária da nossa população.

\section{$\mathrm{O}$ ajuste fiscal}

A mais evidente das restrições feitas ao longo da década de 1990 tem sido a financeira, que vem reduzindo de forma sistemática o gasto público per capita em saúde no Brasil, cujo patamar permaneceu abaixo de países latinoamericanos mais pobres que o nosso.

Abandonou-se por completo a concepção - prevista na Constituição de 1988 - da Seguridade Social, que preconizava um orçamento único e com diversidade de fontes de financiamento para os seus componentes de saúde, assistência e previdência social. Ao restringir o financiamento do setor saúde apenas aos recursos fiscais, ele ficou à mercê da política de ajuste fiscal cada dia mais restritiva, lançando mão de fontes que, como a CPMF, são consideradas de caráter contingencial e sequer vêm sendo integralmente destinadas ao setor.

A ausência de investimento, traço marcante do gasto público nessa década de ajuste, também atingiu de maneira dramática o setor saúde. Os insuficientes recursos de investimento aplicados pelo governo federal - exclusivamente destinados a reequipar, parcialmente, a rede hospitalar pública já existente - passaram a depender de empréstimos externos (principalmente do Banco Mundial), submetendo as definições de prioridades de despesas a serem incorridas em moeda local a negociações com agentes externos não referendados por qualquer instância de representação política nacional. 
A emenda constitucional no 29 (EC29) promulgada em 2000, que fixa compromissos orçamentários para a Saúde, é (mais um) exemplo da capacidade de distorcer propostas antes defendidas pelos setores progressistas e transformá-las em estratégias convenientes para o projeto neoliberal. Mais uma vez, sob a aparência de que os recursos para a saúde aumentarão, e concebendo de forma distorcida uma aspiração de vinculação de recursos, o governo federal perpetra mais uma "reengenharia”, reduzindo sua obrigação e repassando para os estados e municípios a responsabilidade maior no financiamento do setor saúde.

Do ponto de vista da União, aumentar em 5\% o montante investido no setor em relação ao ano de 1999, corrigindo para os anos seguintes pela variação do PIB nominal, não só não significa qualquer avanço no sentido de resolver a insuficiência de recursos para a saúde, como se trata de um enorme retrocesso com relação à Constituição de 1988 e o projeto de emenda constitucional original proposto pelos deputados Eduardo Jorge e Waldir Pires, pelas seguintes razões:

- a EC29 não define a origem dos recursos no âmbito federal, eliminando de vez a vinculação de recursos da Seguridade Social para a Saúde, na medida que os recursos investidos no setor desde 1993 são apenas de origem fiscal; - a ameaça de extinção total das contribuições pelas propostas em pauta para a reforma tributária confirma a destruição da concepção original de seguridade social no financiamento eqüitativo da saúde, previdência e assistência social;

- o patamar de recursos sobre o qual será corrigido em $5 \%$ é sabidamente insuficiente para a saúde. Além de manter esse patamar baixo, o acréscimo de um PIB nominal em franco descenso, dada a recessão econômica, tampouco representa algum cenário animador. Os resultados orçamentários apresentados recentemente ao Conselho Nacional de Saúde demonstram claramente a previsão de redução do patamar federal de recursos calcado no PIB, ao invés de vincular-se às contribuições sociais. A parcela de $20 \%$ retirada da arrecadação de impostos e contribuições sociais para o fundo de estabilização representou, no ano de 2000, quarenta bilhões de reais (quase o dobro do orçamento da saúde para o mesmo ano). 1

Do ponto de vista dos estados, a EC implica uma pequena elevação da sua participação.
Este acréscimo, no entanto, provavelmente não compensará, de um lado, a provável retração de alguns municípios que já destinavam mais do que está previsto na EC e, de outro, a diminuição dos recursos federais pela retirada das contribuições. Além disso, mais uma vez impõe-se uma camisa de força uniforme como se todos os estados tivessem iguais condições de aplicar pelo menos 7\% de suas receitas de impostos e transferências constitucionais, ignorando a retração econômica que afeta a principal fonte de receita dos estados - o ICMS - sem falar no crescente processo de endividamento dos estados. Nesse sentido, não foi estabelecido qualquer tipo de compensação para os estados.

Finalmente, do ponto de vista dos municípios, a vinculação de $7 \%$ até $15 \%$ não provocará aumento de recursos para a saúde: boa parte dos municípios brasileiros já contribui, em média, com $17 \%$ de suas receitas de impostos e transferências. ${ }^{2}$ Ou seja, provavelmente a Lei de Responsabilidade Fiscal afetará o nível do gasto municipal já alcançado na área da saúde, na medida em que o corte de despesas ocorrerá certamente junto às chamadas "despesas comprimíveis".

Por outro lado, é totalmente desconsiderada a enorme heterogeneidade entre os municípios brasileiros na sua capacidade de arrecadação, sobretudo no que diz respeito à suposta "compensação" concedida aos municípios para criar o IPTU "progressivo", fonte que para os municípios pobres não representa absolutamente nada. Ou seja, confirma-se, de forma recorrente, a nossa tese de que a desigualdade entre os municípios será mantida, possivelmente ampliando a iniqüidade do ponto de vista da oferta de serviços de saúde em qualidade e quantidade.

\section{Conclusões}

O sistema de saúde brasileiro ingressa na primeira década do novo século com desafios gigantescos, agravados pelos marcos da política de ajuste neoliberal introduzida na década de 1990. Os avanços formais conquistados na formatação administrativa do Sistema Único de Saúde através das várias normas operacionais instituídas naquela década, apesar da multiplicação de agentes políticos interessados na sua preservação, correm seríssimo risco de serem tragados por fora pela contração de in- 
vestimentos públicos e pela cisão irrecorrível do sistema de saúde.

A implantação da Norma Operacional da Assistência à Saúde (NOAS) tem deixado claro os imensos vazios de oferta de serviços no território nacional. Os atuais mecanismos e valores de custeio da assistência médico-sanitária têm levado a um crescente sucateamento da precária rede assistencial existente e à busca de inexistentes fontes alternativas de financiamento. A sub-remuneração dos profissionais de saúde e a salientada precariedade de suas relações trabalhistas têm fortemente diminuído a sua adesão ao SUS. A associação destes fatores decorrentes da insistência dos definidores da política econômica de atribuir prioridade aos compromissos com as finanças internacionais em detrimento das políticas sociais tem levado a uma crescente ruptura dos preceitos constitucionais que estabeleceram a saúde como direito de todos e dever do Estado, baseado nos princípios da universalidade e igualdade.

Cada vez mais segmentos de maior renda da população, profissionais e prestadores públicos e privados de saúde sonham com a miragem de um dia virem a ingressar ou aumentar sua participação no mundo dos planos e seguros de saúde. É crescente a cisão entre uma assistência para ricos e remediados financiados privadamente (e subsidiados pelo setor público por políticas de renúncia fiscal) por planos e seguros de saúde e uma assistência para pobres financiada por recursos fiscais administrada dentro da lógica do SUS. A fragilidade da capacidade de regulação dos agentes formuladores da política do SUS - Ministério da Saúde e Secretarias Estaduais e Mu- nicipais de Saúde - pela localização desta regulação em uma agência federal independente, a Agência Nacional de Saúde Suplementar, aduba o terreno para que esta cisão prospere. O coração da proposta de reforma sanitária brasileira de construção de um sistema de saúde verdadeiramente único, universal e igualitário, onde as necessidades assistenciais, e não a capacidade de pagar, definem o acesso e utilização dos serviços, pode ter sido gravemente ferido durante os anos noventa.

Ainda há espaços a defender e reconquistar na re-construção do SUS. A reorientação dos marcos da política macroeconômica do país é fundamental para que se liberem os meios e recursos econômicos, políticos e administrativos para a continuidade do esforço brasileiro de reforma setorial democrática. Igualmente deve ser retomada, dando cumprimento aos dispositivos ainda em vigor da Constituição brasileira, a construção da Seguridade Social, onde previdência, saúde e assistência social constituem-se braços integrados e articulados de uma política social abrangente. O sistema de saúde deve continuar a ser concebido e construído como um sistema nacional de saúde, vale dizer que a totalidade de seus recursos, públicos e privados, deve subordinar-se a uma política nacional de saúde. Os sistemas privados devem estar submetidos aos dispositivos regulatórios e normativos que orientam a implementação desta política e articulados com as instâncias subnacionais de gestão e submetidos ao controle social previsto na legislação. A reforma sanitária brasileira ainda é jovem e encontrará forças para avançar. A construção de um Brasil mais justo e saudável continuará ser a sua inspiração primordial.

\author{
Notas \\ 1 Ver dados do Ministério do Planejamento de 2001. \\ 2 Ver levantamento do MS feito em 1998 junto a 1.500 \\ municípios (SIOPS - Sistema de Informações sobre o \\ Orçamento Público em Saúde).
}

